\title{
Salmon louse infestation in wild brown trout populations generates multi-modal mixture distributions
}

\author{
Ola H. Diserud ${ }^{1, *}$, Richard Hedger ${ }^{1}$, Bengt Finstad ${ }^{1,2}$, Ditte Hendrichsen ${ }^{1}$, \\ Arne J. Jensen ${ }^{1}$, Ola Ugedal ${ }^{1}$ \\ ${ }^{1}$ Norwegian Institute for Nature Research (NINA), 7485 Trondheim, Norway
${ }^{2}$ Norwegian University of Science and Technology (NTNU), Department of Biology, 7491 Trondheim, Norway
}

\begin{abstract}
For successful evaluation of the overall effects of salmon louse infestation on brown trout population dynamics, it is crucial to have a realistic understanding of how lice infestation distributions are generated and how they should be interpreted. Here, we simulated the potential effects of spatio-temporal variance in lice larvae densities, temporal variance in sea trout marine migration timing and spatial variance in marine habitat use on lice infestation distributions. We show that, when sampling populations with individual variation in marine behaviour, e.g. from post-smolts to veteran migrants, we must expect multi-modal mixture lice infestation distributions. Applying standard statistical distributions, such as the Poisson, negative binomial or zeroinflated distributions, can be too simplistic and give biased results. Temporary increases in salmon lice load in a given area may have inconsistent effects among individuals of a population and may be critical for vulnerable groups such as post-smolts, dependent on timing. For many analyses, it will be necessary to resolve the contributions from groups of fish with different lice infestation expectations due to spatio-temporal differences in habitat use within the overall mixture distribution. Another consequence is that different data sources, obtained by different methods or sampled at different locations and periods, must be expected to give different lice infestation distributions, even when sampling the same population. We also discuss additional factors that may complicate the interpretation of salmon lice infestation distributions on sea trout, such as lice-induced mortality, and behavioural changes, such as premature return to less saline water for delousing.
\end{abstract}

KEY WORDS: Salmo trutta - Lepeophtheirus salmonis · Anadromy - Marine migration · Aquaculture $\cdot$ Negative binomial distribution $\cdot$ Zero-inflated models

\section{INTRODUCTION}

Brown trout Salmo trutta is an adaptable species found in a wide range of habitats; from streams, rivers and lakes in freshwater to marine coastal areas. In anadromous populations (sea trout), individuals spawn in freshwater and all or parts of the population migrate to marine habitats for feeding after smoltification, often several times during their lifetime (Jonsson \& Jonsson 2011, Thorstad et al. 2015). Smolts typically leave rivers in spring (March

${ }^{*}$ Corresponding author: ola.diserud@nina.no to June) (Thorstad et al. 2016). When smolts and veteran migrants reach the sea they may encounter salmon louse Lepeophtheirus salmonis larvae and risk being infested. Sea trout stay in coastal areas such as estuaries and fjords before returning to freshwater, usually the summer or autumn after they entered the sea (Jensen et al. 2015). The advantages of marine migrations include enhanced growth and fecundity and thereby increased individual fitness, while the costs of sea migration include increased mortality and the energetic investment in smoltifica-

(C) The authors 2020. Open Access under Creative Commons by Attribution Licence. Use, distribution and reproduction are unrestricted. Authors and original publication must be credited. 
tion and migration (Gross et al. 1988, Jensen et al. 2019). The most beneficial strategy varies among individuals and populations (Thorstad et al. 2016, Nevoux et al. 2019). Populations can change their migratory habits when major environmental factors such as water flow change (Sandlund \& Jonsson 2016), as can the tendency for marine migration versus residency (Solomon 2006).

Salmon lice are external parasites occurring naturally on salmonids in the marine environment. They remove mucus, skin and tissue from the host. As skin damage and lesions develop, host fish may be vulnerable to osmoregulatory dysfunction, physiological stress, secondary microbial infections and ultimately increased marine mortality (Pike \& Wadsworth 1999, Finstad \& Bjørn 2011, Thorstad et al. 2015). Salmon lice from fish farms are a major threat for wild salmonids (Forseth et al. 2017) because farmed salmon act as hosts for salmon lice and increase the production of infective salmon louse larvae in coastal areas (Taranger et al. 2015). High lice infestation pressure from salmon farms has been shown to increase the number of lice on wild salmonids (Serra-Llinares et al. 2014, Shephard et al. 2016, Vollset et al. 2018a), and is especially pertinent for many sea trout populations (Thorstad \& Finstad 2018, Nevoux et al. 2019) because sea trout typically remain in the same coastal areas where farms are situated during their stay in the marine habitat. High levels of lice infestation may also lead to premature migratory return to brackish water or freshwater (Bjørn et al. 2001, Wells et al. 2007, Serra-Llinares et al. 2018, 2020). The state of 430 Norwegian sea trout populations has recently been evaluated by the Norwegian Scientific Advisory Committee for Atlantic Salmon (Anon. 2019), who found that nearly half of the populations (208) were in a poor or very poor state. Salmon lice had the largest negative impact on sea trout populations among anthropogenic impact factors (Anon. 2019), affecting $91 \%$ of the classified populations.

Data on salmon louse infestation levels on sea trout hosts are used when evaluating effects of infestive salmon louse larvae densities in wild salmonid populations (Vollset et al. 2018b). For successful evaluation of the effect of salmon lice on sea trout population dynamics, it is crucial to have a realistic understanding of the salmon louse infestation process under different scenarios of lice larvae densities. Lice infestation models exist for Atlantic salmon (Sandvik et al. 2016, Kristoffersen et al. 2018) but because the marine habitat use and behaviour of sea trout differs substantially from that of Atlantic salmon (Vollset et al. 2017), a dedicated lice infesta- tion model for sea trout is required. In addition, controlled infestation challenges suggest that different host species may differ in their susceptibility to salmon lice (Bui et al. 2018).

Sea trout display a diversity of marine migration patterns and life-history strategies (Aldvén et al. 2015, Eldøy et al. 2015). Major challenges when analysing catch sample lice infestation distributions for a coastal area are that sampled fish may have been at sea for varying lengths of time, they may have utilized or moved between different coastal habitats with varying lice larvae densities from near shore and brackish waters to open water areas close to salmon farms, and they may originate from different populations with different migration histories. Additionally, fish are not necessarily captured close to the site where they were infested. Therefore, samples of sea trout collected by different methods, at different coastal locations and over different periods can give very different lice infestation sample distributions, even if the spatio-temporal lice larvae distributions at sea are the same. Samples may consist of several sub-populations with potentially very different lice infestation rates and distributions, depending on marine residence time and habitat use. Salmon louse infestation in wild sea trout populations must therefore be expected to generate multi-modal mixture distributions. Most studies of salmon louse infestation distributions either use the Poisson (Murray 2002, Patanasatienkul et al. 2015) or the negativebinomial distribution (Heuch et al. 2011, Vollset et al. 2017, 2018a); these approaches may be too simplistic because they assume all lice counts are observations from the same distribution. Alternatively, zero-inflated distributions, which can be considered to be a 2-modal version of the mixture distribution where the 'false zeros' are from a group of fish that have not been exposed to salmon louse, have been used (Kristoffersen et al. 2013, Helland et al. 2015).

Explicit modelling of the spatio-temporal marine habitat use and associated lice infestation probability of individual sea trout may become too complex to handle and parameterize in a reliable way. An alternative may be to model the expected contributions from different spatio-temporal groups of fish to the total lice infestation mixture distribution, where the relative contributions from the different groups will depend on when and where the fish are sampled. In order to correctly interpret a lice infestation distribution sampled in nature, it is important to acknowledge that this will most often be a mixture distribution consisting of different groups of fish with different distributional parameters. 
In the present study, we illustrate how salmon louse infestation mixture distributions can be generated by simulating potential effects from temporal variance in sea trout marine migration timing and spatial variance in marine habitat use. We also discuss additional factors that further complicate the interpretation of lice infestation distributions, such as lice-induced mortality and behavioural changes such as delousing migrations to brackish water or freshwater, which may truncate the distribution.

\section{METHODS}

Salmon louse infestation distributions were simulated under 3 conditions: (1) a sea trout population with a homogeneous infestation pressure (utilizing the same marine habitat for the same period of time); (2) a sea trout population exposed to a temporally varying lice infestation pressure; (3) a sea trout population consisting of sub-populations experiencing different lice infestation pressures. Models were fitted assuming independence between lice infestations and assuming no effect of host size on infestation probability. All simulations and calculations were performed using the statistical software $\mathrm{R} \mathrm{v}$. 3.6.2 (R Core Team 2019).

\subsection{Lice infestation distributions for homogeneous groups of fish}

Lice counts could be modelled as a Poisson process if these were homogeneous with no overdispersion, but data on lice counts show that the variance in the lice infestation distribution is larger than expected for the Poisson distribution (Helland et al. 2015). The negative binomial distribution has been considered appropriate for situations like this and has become the prevailing method of modelling aggregation of parasites per host (Yakob et al. 2014). This overdispersion can, for example, be caused by small scale spatial variation in lice density or variation in individual behaviour among fish (such as differing horizontal and vertical migration patterns).

We modelled the probability that lice abundance $X$ equals $x$ for a homogeneous group of fish using a negative binomial probability mass function $P$, with mean $\mu$, dispersion parameter $\theta$ (also called size or $n$ ) and variance $\sigma^{2}=\mu+\mu^{2} / \theta$ (which is always greater than the mean):

$$
P(X=x)=\frac{\Gamma(x+\theta)}{\Gamma(x+1) \Gamma(\theta)}\left(\frac{\theta}{\theta+\mu}\right)^{\theta}\left(\frac{\mu}{\theta+\mu}\right)^{X}
$$

The negative binomial distribution approaches the Poisson distribution when $\theta$ becomes large. The increase in variance:mean ratio for the negative binomial relative to the Poisson distribution (where this ratio equals 1 ) is described by the mean:dispersion ratio $c=\mu / \theta=\sigma^{2} / \mu-1$.

For a sea trout that has been in a given marine habitat in Week $i$, the number of salmon louse larvae attached during this week $X_{i}$ was assumed to have a negative binomial distribution with expected lice infestation $\mu_{i}$ and dispersion parameter $\theta_{i}$. Distributions were created based on numbers from real surveillance data, using low and high infestation weeks (Gjelland et al. 2014, their Table 3). For the illustration of a 'low-infestation week', realized lice infestations for a group of sea trout $\left(\mathrm{n}_{\text {Low }}=400\right)$ were simulated from a negative binomial distribution with expectation $\mu_{\text {Low }}=4$ lice per host and dispersion parameter $\theta_{\text {Low }}=0.22$. For the 'high-infestation week', the same number of fish $\left(\mathrm{n}_{\text {High }}=400\right)$ were simulated from a distribution with expectation $\mu_{\text {High }}=$ 138 and dispersion $\theta_{\text {High }}=2$. To illustrate the large estimation uncertainty expected from skewed distributions like these, even when assuming ideal random sampling, repeated samples from the same distribution were simulated 1000 times and the parameters of the negative binomial distribution estimated from the simulated samples.

\subsection{Lice infestation distributions accumulated over a period with varying infestation intensities}

Lice infestation distributions were then simulated for a group of fish that migrated to sea at the same time and stayed together in the same marine habitat over several weeks (referred to here as an 'ocean group'), but were exposed to varying lice larvae densities during this period. For simplicity, each week at sea was assumed to be an independent 'experiment', where the number of lice attaching in different weeks and on different fish was independent.

The accumulated number of lice $X$ attached to a fish over $k$ weeks was modelled as the sum of independent negative-binomially distributed variables $X=X_{1}+X_{2}+\ldots+X_{k}$, where parameters $\mu_{i}$ and $\theta_{i}$ varied among weeks as a function of varying lice larvae density levels, still assuming the mean:dispersion ratio $c=\mu_{i} / \theta_{i}=\sigma^{2}{ }_{i} / \mu_{i}-1$. The sum $X$ therefore had a negative binomial distribution, with parameters

$\mu=\sum_{i=1}^{k} \mu_{i}$ and $\theta=\sum_{i=1}^{k} \theta_{i}=\mu / C$. 
Here, the accumulation of salmon lice on individual fish was simulated for $k=3$ weeks, where the first week was parameterized to be similar to the lowinfestation week for the homogenous group (Section 2.1.), i.e. $\left(\mu_{1}, \theta_{1}\right)=(4,0.22)$, while the parameters for the next 2 weeks, $\left(\mu_{2}, \theta_{2}\right)=(80,1.06)$ and $\left(\mu_{3}, \theta_{3}\right)=$ $(54,0.72)$, were adjusted so that the accumulated lice infestation over 3 weeks corresponded to the highintensity sample (Week 24, Gjelland et al. 2014, their Table 3).

\subsection{Mixture distribution when lice infestation expectations differ among ocean groups}

All fish who migrate out the same week and stay in the same marine habitat for the whole period have so far been assumed to have the same expected accumulated lice infestation and can be considered to be from the same statistical population. In contrast, samples obtained from gill-nets or fyke traps at sea, or sea trout captured when returning to freshwater, will be composed of a mixture of different spatiotemporal ocean groups with different parameters for their respective accumulated negative binomial distributions.

To illustrate potential characteristics of the mixture distribution, 3 ocean groups with large differences in accumulated lice infestation distribution parameters were simulated. Lice infestation was simulated to decrease over 3 weeks, with weekly expectations of 100, 50 and 10 lice respectively, and the weekly variances were set low to emphasize the multi-modal characteristic of the mixture distribution. These ocean groups can be considered to have migrated to sea for 3 consecutive weeks (temporal groups), but the same mixture distribution can be obtained by assuming that the fish stayed for the same period in different marine habitats with differences in expected lice infestation (spatial groups).

\section{RESULTS}

\subsection{Simulated lice infestation distributions for homogeneous groups of fish}

The 'low-infestation week' simulation gave a prevalence of $50 \%$ and a mean intensity of $8.4( \pm 12.2$ SD; max. = 80), corresponding approximately to the observations for Week 22 (Gjelland et al. 2014, their Table 3) (Fig. 1a). The simulated 'high-infestation week' sample had a prevalence of $100 \%$ and a mean intensity of $139( \pm 102 \mathrm{SD}$; max. = 662) (Fig. 1b), corresponding to Week 24 (Gjelland et al. 2014, their Table 3) when assuming that these fish had just 1 week of lice exposure.

From repeated simulations from the low-infestation distribution presented above, with parameters $\left(\mu_{\text {Low }}, \theta_{\text {Low }}\right)=(4,0.22)$ and sample size 400 , approximate $95 \%$ confidence intervals $[2.7,5.9]$ and $[0.168$, 0.280] were obtained for $\mu_{\text {Low }}$ and $\theta_{\text {Low }}$ respectively. For the high-infestation simulations with parameters $\left(\mu_{\text {High }}, \theta_{\text {High }}\right)=(138,2)$ and sample size 400 , approximate $95 \%$ confidence intervals $[125,148]$ and $[1.72$, 2.42] were obtained.
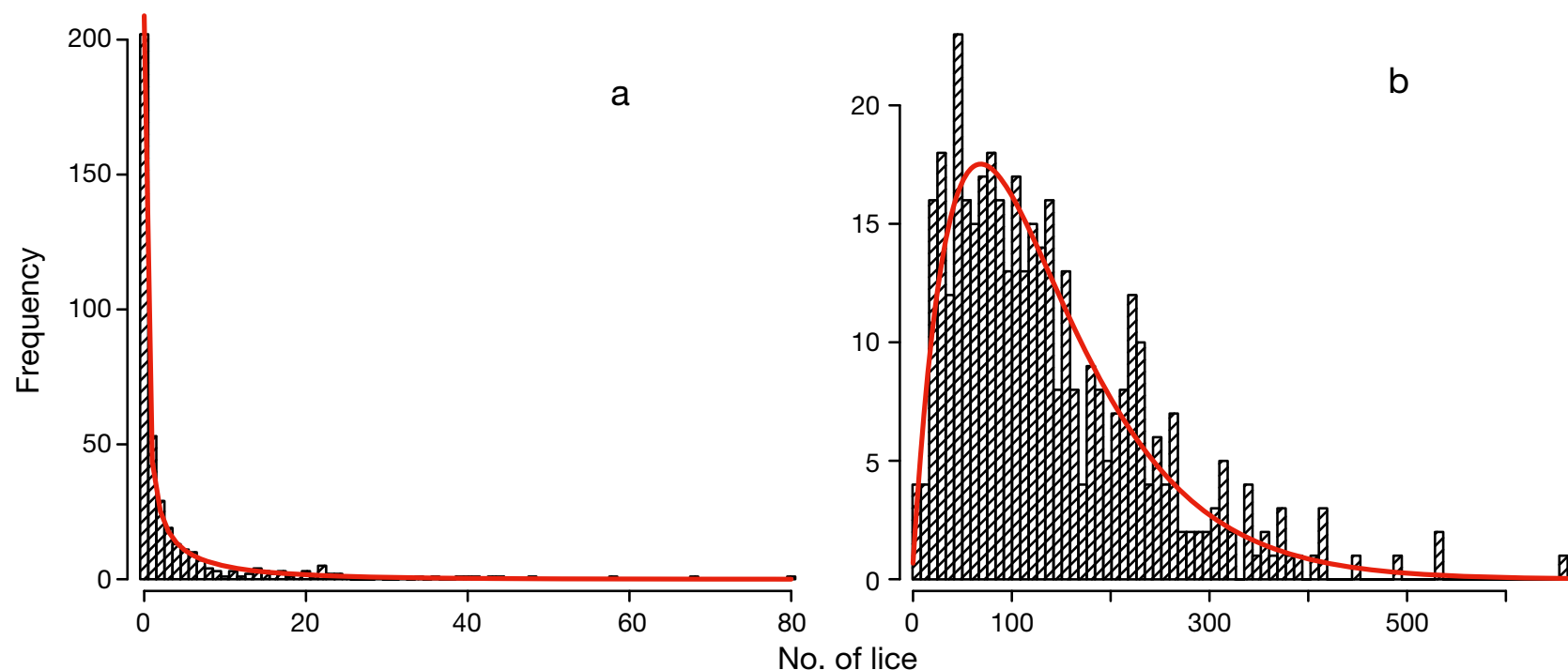

Fig. 1. Simulated salmon lice infestation distributions for a group of sea trout from (a) a low-infestation week and (b) a highinfestation week. Red lines: binomial distributions used to simulate the lice abundances 


\subsection{Simulated distributions for a period with varying lice infestation expectations}

Fig. 2 shows the simulated lice infestations for each of the 3 weeks, with weekly parameters $\left(\mu_{1}, \theta_{1}\right)=$ $(4,0.22),\left(\mu_{2}, \theta_{2}\right)=(80,1.06)$ and $\left(\mu_{3}, \theta_{3}\right)=(54,0.72)$, respectively, and the accumulated lice infestation distribution after 3 weeks. Expected accumulated lice infestation after 3 weeks equals the sum of the 3 single-week expectations, i.e. 138 lice, and the shape of the negative binomial distribution (Fig. 2d) was similar to the high-infestation week in Section 3.1. (Fig. 1b).
This approach can be refined if supporting data on lice development stage is available, which may be used to estimate expected length of sea residency.

\subsection{Simulated mixture distribution when lice infestation expectations differ among groups}

Fig. 3 shows the simulated ocean group that migrated to sea in Week 1 and accumulated lice in all 3 weeks (Fig. 3a; $\mu_{123}=\mu_{1}+\mu_{2}+\mu_{3}=160$ lice), the ocean group that entered the sea in Week 2 and
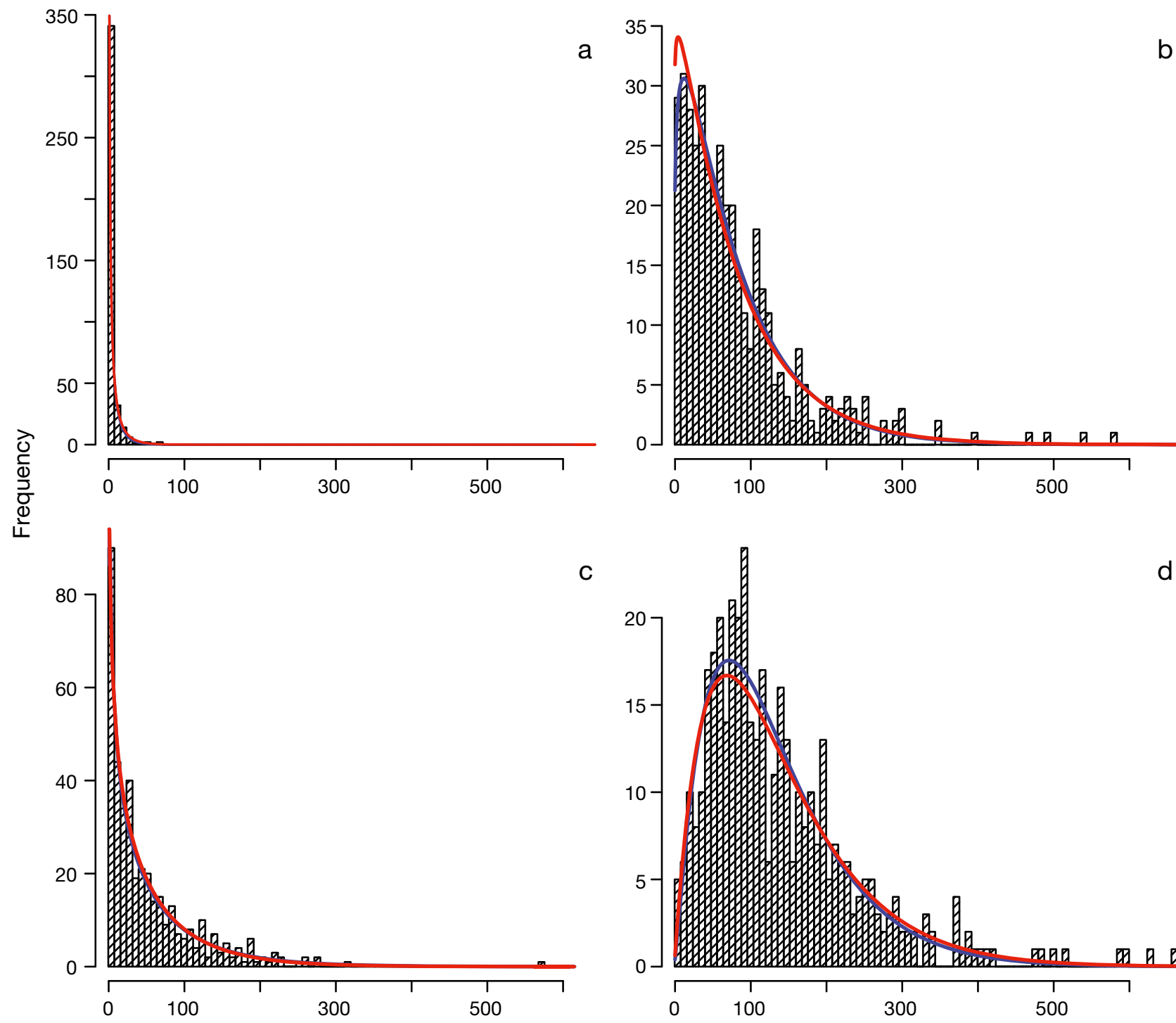

C

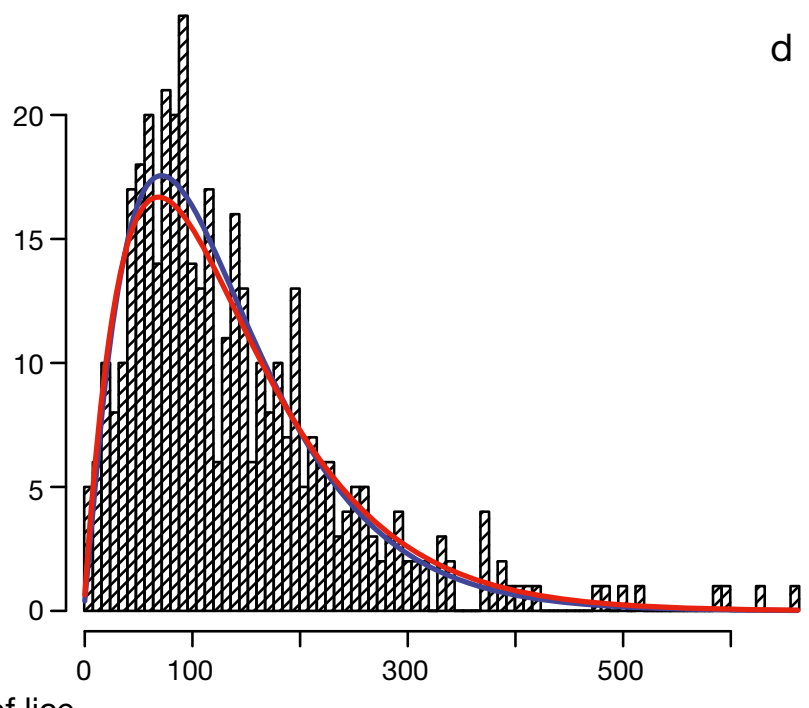

No. of lice

Fig. 2. (a,b,c) Weekly lice infestations for Weeks 1 to 3, respectively, and (d) the total accumulated lice abundance distribution after the 3 weeks. Expected means for the 3 weeks are 4, 80 and 54, respectively, and 138 for the total distribution. Red lines: distributions used for the simulation from and the theoretical distribution for the 3 week accumulated distribution; blue lines: negative binomial distributions fitted directly to the simulated samples (only visible in panels $b$ and d) 

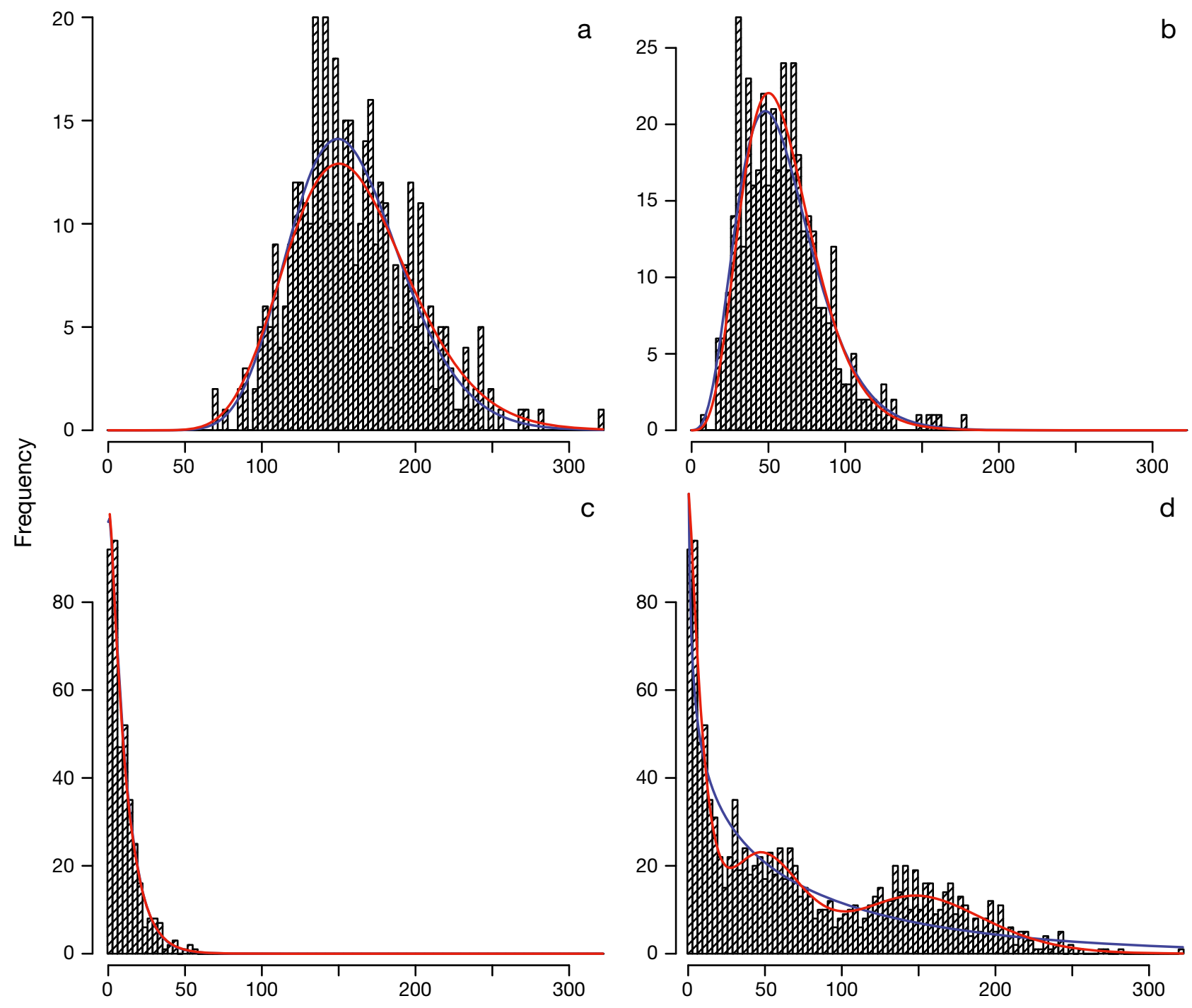

No. of lice

Fig. 3. Accumulated lice infestation distributions in Week 3 for the 3 temporal ocean groups: (a) all 3 weeks; (b) Weeks 2 and 3; (c) Week 3 only. (d) The mixture distribution after Week 3 if the groups are assumed to be of equal size. Red lines: theoretical distribution from which we simulated; blue lines: fitted negative binomial distributions

accumulated lice in Weeks 2 and 3 (Fig. $3 b_{;} \mu_{23}=60$ lice), the ocean group that was infested by lice in Week 3 only (Fig. $3 c_{i} \mu_{3}=10$ lice), and the mixture distribution resulting if the 3 temporal ocean groups were of equal size at time of sampling (Fig. 3d). The mixture distribution had 3 modes, with a mode contributed from each of the groups.

\section{DISCUSSION}

In this paper, we have illustrated the challenge of correctly parameterizing salmon louse infestation dis- tributions for sea trout. By explicitly considering the biological mechanisms rather than just fitting standard distributions to lice counts from catches of wild sea trout lice, infestation distributions observed in nature can be recreated. Model simulations show that multi-modal mixture distributions must be expected for sea trout lice infestations when sampling from populations with individual differences in migration timing and marine habitat use. As long as the contributions from the different ocean groups to a catch sample are representative of the situation for a sea trout population in nature, covering spatial variation in lice larvae density and individual variation 
in sea trout migratory behaviour, parameters from single-group distributions can be determined. One advantage with this approach is that individual movements and infestations do not have to be modelled explicitly. Knowledge of single-group distributions can be crucial when evaluating the impacts of human disturbance in the marine habitat, vital for sustainable management. For example, a temporal peak in lice releases from Atlantic salmon farms can affect sea trout ocean groups very differently, depending on marine habitat choice relative to farm location and timing of migration relative to the peak in lice releases. This modelling approach can also be applied for other species with similar marine residence time and habitat use as sea trout, such as Arctic char Salvelinus alpinus (Jensen et al. 2012) or Pacific salmonids.

With such skewed distributions and large natural stochasticity, it will be futile to hope for precise predictions of lice infestation, but possible scenarios caused by variance in salmon louse infestation pressure can still be illustrated. A good understanding of the lice infestation process and resultant distributions, beyond mean intensity and prevalence, is essential when evaluating overall effects of increasing salmon louse infestation pressure on sea trout population dynamics and composition. Salmon louse infestation will not only affect the marine mortality and growth of sea trout (Gjelland et al. 2014, Halttunen et al. 2018), but may also affect subsequent life history traits such as delayed maturation and decreased fecundity due to the reduction in marine growth, increased freshwater mortality and reduced degree of anadromy. The delayed effects from salmon louse infestation at sea on life history traits in freshwater have so far not been explicitly studied for sea trout, but are expected to be very adverse for abundance and size distributions. Vollset et al. (2014) showed that age at maturity for Atlantic salmon is influenced by growth rate at sea and Tveiten et al. (2010) showed that lice infestation delayed Arctic char maturation, both comparable salmonid species.

There are inevitably several factors that affect salmon louse infestation in sea trout that have not been explicitly accounted for. Some factors are fairly straightforward to include, but were not considered at this stage to emphasize our main points and not make the simulations more complicated than necessary. First, salmon louse infestation levels are shown to increase with the size of the fish (Jaworski \& Holm 1992, Vollset et al. 2017). Size dependency can be accounted for by assuming a surface area proportionality (Jaworski \& Holm 1992) in the expected lice infestation. Second, dependence among lice infestations can affect the variance of the distribution, either as within-fish dependency, where ongoing lice infestation may alter fish behaviour and thereby the probability of more lice attaching, or as among-fish dependency, such as schooling or other correlated behaviour. Third, effects of salmon louse infestation on sea trout marine mortality and behaviour (Gjelland et al. 2014, Halttunen et al. 2018) will affect the shape of the lice infestation distribution; additional lice-induced mortality and premature returns to freshwater by highly infested trout will right-truncate the distribution in marine catches, while fish returning to sea from delousing visits to less saline water will inflate the left tail of the distribution. Right-truncation means that there will be fewer fish with high lice infestation levels than expected from the lice abundance mixture distribution, and that estimated prevalence and mean intensity from a catch sample will be biased. In addition, infested fish have been found to reside closer to freshwater while at sea (Birkeland \& Jakobsen 1997, Serra-Llinares et al. 2018, 2020), forcing the sea trout away from some of the most beneficial growth habitats as well as reducing the continued infestation.

Potential sampling effects can also disturb a proper description of lice infestation distributions for sea trout; lice can be rubbed off when the fish are caught and handled, or lice can be overlooked during counting, leading to a systematic underestimation of lice infestation. Where in the marine habitat the trout are caught, e.g. close to the river mouth or further out, can have a large effect on the proportions of the different spatio-temporal groups in the sample and thereby also the observed mixture distribution. There is also a possibility that catch probability can be affected by lice infestation, i.e. infested fish may be more likely to be observed by some sampling methods. Different data sources, obtained by different sampling methods at different locations and collected over different periods, must therefore be expected to give different lice infestation distributions even if the sampled fish have migrated to the same coastal region. For example, fish caught mid-season just outside the river mouth could consist of either recently seaward migrated fish with no or few lice or fish returned prematurely from the sea due to high lice infestations. The sampling design must therefore be well planned in order to obtain representative samples and yield the requested information. 
The issue of estimating parameters from a mixture negative binomial distribution will only be discussed briefly here. To obtain reliable estimates of lice infestation distribution parameters for sea trout populations, we depend on intensive and targeted sampling. For a single ocean group of fish exposed to the same expected salmon louse infestation intensity, e.g. from sentinel cages where fish are kept in cages at sea for a given period to monitor lice pressure, a regular unimodal negative binomial distribution can be fitted to provide time- and placespecific parameter estimates. When data comes from gill-net or fyke catches, or from fish caught when returning to freshwater, the sample will probably be composed of fish from several ocean groups, i.e. observations from a negative binomial mixture distribution. The question is then whether it is possible to identify the different spatio-temporal ocean groups, based on data such as lice development stage and type of fish, since smolts can use different habitats to veteran migrants (Eldøy et al. 2015) and females and males may prioritize marine habitat use differently (Thorstad et al. 2016). Additional supporting data such as variance in lice larvae densities and sea trout marine migration timing and habitat use may also be useful when determining the number of, and relative contribution from, different ocean groups. If the goal of the analyses, for example, is to evaluate the effect of a change in lice larvae density limited in time and space, the sampling design or data sorting needs to be considered thoroughly so that the observations analysed are representative for the ocean groups exposed to this change. When the sample is composed of a large number of spatio-temporal ocean groups, the mixture distribution itself can be represented by a single negative binomial distribution if the expectations from the different ocean groups can be assumed to be gamma distributed. If knowledge of the single-group parameters is not required, fitting the resultant mixture distribution directly may suffice for some analyses.

Considerable variation must be expected in samples of salmon louse abundance in wild sea trout, as well as deviations from standard statistical distributions. Even if the number of complicating factors may seem numerous, most of them can be handled in a simulation model, but dedicated studies are required to sort out the various contributions from real samples. Quantifying lice infestation in sea trout with summary statistics like prevalence and intensity can be misleading, since the distributions can be mixed, multi-modal and truncated. Therefore, the whole lice infestation distribution and the potential relative contribution from the different groups of fish have to be described.

To predict potential effects of increased salmon lice loads on sea trout populations, we first need to understand how varying lice larvae densities in seawater and individual sea trout migration behaviour, as well as how we sample, can affect the observed lice infestation distributions. Degree of anadromy, migration timing and duration, marine habitat use and encountered lice larvae densities may vary considerably among sea trout populations, both within a region and along environmental gradients (Ferguson et al. 2019), reducing the generalization potential from data rich to data poor rivers and populations. Knowing how different spatio-temporal factors may affect the parameters of the salmon louse infestation distribution will be crucial for a robust interpretation of lice count data, evaluation of the effect of salmon louse on sea trout population dynamics and composition, and finally, a sustainable management of sea trout populations.

Acknowledgements. We thank the Environment Agency of Norway and the Ministry of Trade, Industry and Fisheries for their financial contribution. This work was also supported financially by the Norwegian Institute for Nature Research through the Strategic Institute Initiative 'Interactions between aquaculture and wild salmonids'.

\section{LITERATURE CITED}

Aldvén D, Hedger R, Økland F, Rivinoja P, Höjesjö J (2015) Migration speed, routes, and mortality rates of anadromous brown trout Salmo trutta during outward migration through a complex coastal habitat. Mar Ecol Prog Ser 541:151-163

Anon. (2019) Classification of the state of 430 Norwegian sea trout populations. Temarapport no. 7. Norwegian Scientific Advisory Committee for Atlantic Salmon. https://brage.nina.no/nina-xmlui/handle/11250/2629316

Birkeland K, Jakobsen PJ (1997) Salmon lice, Lepeophtheirus salmonis, infestation as a causal agent of premature return to rivers and estuaries by sea trout, Salmo trutta, juveniles. Environ Biol Fishes 49: 129-137

Bjørn PA, Finstad B, Kristoffersen R (2001) Salmon lice infection of wild sea trout and Arctic char in marine and freshwaters: the effects of salmon farms. Aquacult Res 32: 947-962

* Bui S, Halttunen E, Mohn AM, Vågseth T, Oppedal F (2018) Salmon lice evasion, susceptibility, retention, and development differ amongst host salmonid species. ICES J Mar Sci 75:1071-1079

Eldøy SH, Davidsen JG, Thorstad EB, Whoriskey F and others (2015) Marine migration and habitat use of anadro- 
mous brown trout (Salmo trutta). Can J Fish Aquat Sci 72 : 1366-1378

Ferguson A, Reed TE, Cross TF, McGinnity P, Prodöhl PA (2019) Anadromy, potamodromy and residency in brown trout Salmo trutta: the role of genes and the environment. J Fish Biol 95:692-718

Finstad B, Bjørn PA (2011) Present status and implications of salmon lice on wild salmonids in Norwegian coastal zones. In: Jones S, Beamish R (eds) Salmon lice: an integrated approach to understanding parasite abundance and distribution. Wiley-Blackwell, Oxford, p 281-305

Forseth T, Barlaup BT, Finstad B, Fiske P and others (2017) The major threats to Atlantic salmon in Norway. ICES J Mar Sci 74:1496-1513

Gjelland KØ, Serra-Llinares RM, Hedger RD, ArechavalaLopez P and others (2014) Effects of salmon lice infection on the behaviour of sea trout in the marine phase. Aquacult Environ Interact 5:221-233

Gross MR, Coleman RM, McDowall RM (1988) Aquatic productivity and the evolution of diadromous fish migration. Science 239:1291-1293

Halttunen E, Gjelland KØ, Hamel S, Serra-Llinares RM and others (2018) Sea trout adapt their migratory behaviour in response to high salmon lice concentrations. J Fish Dis 41:953-967

* Helland IP, Uglem I, Jansen PA, Diserud OH, Bjørn PA, Finstad B (2015) Statistical and ecological challenges of monitoring parasitic salmon lice infestations in wild salmonid fish stocks. Aquacult Environ Interact 7: 267-280

Heuch PA, Gettinby G, Revie CW (2011) Counting sea lice on Atlantic salmon farms - empirical and theoretical observations. Aquaculture 320:149-153

Jaworski A, Holm JC (1992) Distribution and structure of the population of sea lice, Lepeophtheirus salmonis Krøyer, on Atlantic salmon, Salmo salar L., under typical rearing conditions. Aquacult Fish Manage 23:577-589

Jensen AJ, Finstad B, Fiske P, Hvidsten NA, Rikardsen AH, Saksgård L (2012) Timing of smolt migration in sympatric populations of Atlantic salmon (Salmo salar), brown trout (Salmo trutta), and Arctic char (Salvelinus alpinus). Can J Fish Aquat Sci 69:711-723

Jensen AJ, Diserud OH, Finstad B, Fiske P, Rikardsen AH (2015) Between-watershed movements of two anadromous salmonids in the Arctic. Can J Fish Aquat Sci 72 : 855-863

Jensen AJ, Finstad B, Fiske P (2019) The cost of anadromy: marine and freshwater mortality rates in anadromous Arctic char and brown trout in the Arctic region of Norway. Can J Fish Aquat Sci 76:2408-2417

Jonsson B, Jonsson N (2011) Ecology of Atlantic salmon and brown trout. Habitat as a template for life histories. Springer, New York, NY

Kristoffersen AB, Rees EE, Stryhn H, Ibarra R, Campisto JL, Revie CW, St-Hilaire S (2013) Understanding sources of sea lice for salmon farms in Chile. Prev Vet Med 111: 165-175

Kristoffersen AB, Qviller L, Helgesen KO, Vollset KW, Viljugrein H, Jansen PA (2018) Quantitative risk assessment of salmon louse-induced mortality of seawardmigrating post-smolt Atlantic salmon. Epidemics 23: 19-33

Murray AG (2002) Using observed load distributions with a simple model to analyse the epidemiology of sea lice
(Lepeophtheirus salmonis) on sea trout (Salmo trutta). Pest Manag Sci 58:585-594

Nevoux M, Finstad B, Davidsen JG, Finlay R and others (2019) Environmental influences of life history strategies in partial anadromous brown trout (Salmo trutta, Salmonidae). Fish Fish 20:1051-1082

*Patanasatienkul T, Sanchez J, Rees EE, Pfeiffer D, Revie CW (2015) Space-time cluster analysis of sea lice infestation (Caligus clemensi and Lepeophtheirus salmonis) on wild juvenile Pacific salmon in the Broughton Archipelago of Canada. Prev Vet Med 120:219-231

* Pike AW, Wadsworth SL (1999) Sea lice on salmonids: their biology and control. Adv Parasitol 44:233-337

R Core Team (2019) R: a language and environment for statistical computing. Version 3.6.2. R Foundation for Statistical Computing, Vienna

F Sandlund OT, Jonsson B (2016) Life history plasticity: migration ceased in response to environmental change? Ecol Freshwat Fish 25:225-233

Sandvik AD, Bjørn PA, Ådlandsvik B, Asplin L and others (2016) Toward a model-based prediction system for salmon lice infestation pressure. Aquacult Environ Interact 8:527-542

Serra-Llinares RM, Bjørn PA, Finstad B, Nilsen R, Harbitz A, Berg M, Asplin L (2014) Salmon lice infection on wild salmonids in marine protected areas: an evaluation of the Norwegian 'National Salmon Fjords'. Aquacult Environ Interact 5:1-16

* Serra-Llinares RM, Freitas C, Nilsen R, Elvik KMS and others (2018) Towards direct evidence of the effects of salmon lice (Lepeophtheirus salmonis Krøyer) on sea trout (Salmo trutta L.) in their natural habitat: proof of concept for a new combination of methods. Environ Biol Fishes 101:1677-1692

* Serra-Llinares RM, Bøhn T, Karlsen Ø, Nilsen R and others (2020) Impacts of salmon lice on mortality, marine migration distance and premature return in sea trout. Mar Ecol Prog Ser 635:151-168

Shephard S, MacIntyre C, Gargan P (2016) Aquaculture and environmental drivers of salmon lice infestation and body condition in sea trout. Aquacult Environ Interact 8: 597-610

Solomon DJ (2006) Migration as a life-history strategy for the sea trout. In: Harris G, Milner N (eds) Sea trout: biology, conservation and management. Blackwell Publishing, Oxford, p 224-233

Taranger GL, Karlsen Ø, Bannister RJ, Glover KA and others (2015) Risk assessment of the environmental impact of Norwegian Atlantic salmon farming. ICES J Mar Sci 72: 997-1021

Thorstad EB, Finstad B (2018) Impacts of salmon lice emanating from salmon farms on wild Atlantic salmon and sea trout. NINA report 1449:1-22

Thorstad EB, Todd CD, Uglem I, Bjørn PA and others (2015) Effects of salmon lice Lepeophtheirus salmonis on wild sea trout Salmo trutta-a literature review. Aquacult Environ Interact 7:91-113

Thorstad EB, Todd CD, Uglem I, Bjørn PA and others (2016) Marine life of the sea trout. Mar Biol 163:47

Tveiten H, Bjørn PA, Johnsen HK, Finstad B, McKinley RS (2010) Effects of sea louse Lepeophtheirus salmonis on temporal changes in cortisol, sex steroids, growth and reproductive investment in Arctic charr Salvelinus alpinus. J Fish Biol 76:2318-2341

Vollset KW, Barlaup BT, Skoglund H, Normann ES, Skilbrei 
OT (2014) Salmon lice increase the age of returning Atlantic salmon. Biol Lett 10:20130896

Vollset KW, Halttunen E, Finstad B, Karlsen Ø, Bjørn PA, Dohoo I (2017) Salmon lice infestation on sea trout predicts infestations on migrating salmon post-smolts. ICES J Mar Sci 74:2354-2363

Vollset KW, Qviller L, Skår B, Barlaup BT, Dohoo I (2018a) Parasitic sea louse infestations on wild sea trout: separating the roles of fish farms and temperature. Parasit Vectors 11:609

Vollset KW, Dohoo I, Karlsen $\varnothing$, Halttunen E and others (2018b) Food for thought: disentangling the role of sea

Editorial responsibility: Tim Dempster,

Melbourne, Victoria, Australia lice on the marine survival of Atlantic salmon. ICES J Mar Sci 75:50-60

*Wells A, Grierson CE, Marshall L, MacKenzie M and others (2007) Physiological consequences of 'premature freshwater return' for wild sea-run brown trout (Salmo trutta) post-smolts infested with sea lice (Lepeophtheirus salmonis). Can J Fish Aquat Sci 64: 1360-1369

*Yakob L, Soares Magalhaes RJ, Gray DJ, Milinovich G and others (2014) Modelling parasite aggregation: disentangling statistical and ecological approaches. Int J Parasitol 44:339-342

Submitted: May 5, 2020; Accepted: August 26, 2020

Proofs received from author(s): October 19, 2020 